\title{
ARITMÉTICA NAS ESCOLAS PRIMÁRIAS GAÚCHAS NA PRIMEIRA METADE DO SÉCULO 20: O ENSINO PRESCRITO
}

\author{
Elisabete Zardo Búrigo \\ Universidade Federal do Rio Grande do Sul, Brasil.
}

\begin{abstract}
Resumo
Da proclamação da República, no Brasil, em 1889, até a decretação da Lei Orgânica sobre o Ensino Primário, em 1946, as normatizações sobre o ensino primário foram incumbência dos Estados que compunham a federação. Neste texto examinam-se as normatizações estabelecidas, neste período, no Estado do Rio Grande do Sul, no período conhecido como Primeira República (1889-1930) e na chamada Era Vargas (1930-1945), enfocando as prescrições relativas ao ensino da Aritmética. São estabelecidas conexões entre as orientações programáticas e metodológicas para a Aritmética e as políticas governamentais de expansão, ordenamento, modernização e controle do ensino primário.

Palavras-chave: história da educação, história das disciplinas escolares, ensino primário, aritmética, educação matemática.
\end{abstract}

\section{ARITHMETIC IN RIO GRANDE DO SUL PRIMARY SCHOOLS IN THE FIRST HALF OF THE $20^{\text {TH }}$ CENTURY: PRESCRIBED TEACHING}

\section{Abstract}

Since the proclamation of the Republic, in Brazil, in 1889, until the enactment of the Organic Law on Primary Education in 1946, the norms on primary schooling were on the responsibility of the States that make up the federation. The text examines the norms established in this period, in the state of Rio Grande do Sul, in the period known as the First Republic (1889-1930) and in the period named Era Vargas (1930-1945), focusing on the specifications concerning the teaching of Arithmetic. Connections are established between the programmatic and methodological guidelines for the Arithmetic and government policies of expansion, modernization, planning and control of primary education.

Key-words: history of education, history of school subjects, primary school, arithmetic, mathematics education.

\section{ARITMÉTICA EN LAS ESCUELAS PRIMARIAS DE RIO GRANDE DO SUL EN LA PRIMERA MITAD DEL SIGLO 20: LA ENSEÑANZA PRESCRITA}

Resumen

Desde la proclamación de la República, en Brasil, en 1889, hasta la promulgación de la Ley Orgánica de Educación Primaria en el año 1946, las normas acerca de la educación primaria 
estuvieron en la responsabilidad de los Estados que componen la federación. El texto examina las normas establecidas en este periodo, en el Estado de Rio Grande do Sul, en el período conocido como la Primera República (1889-1930) y en la Era Vargas (1930-1945), centrándose en las prescripciones para la enseñanza de la Aritmética. Se establecen conexiones entre las líneas programáticas y metodológicas para la Aritmética y las políticas gubernamentales de expansión, modernización, planificación y control de la educación primaria.

Palabras-clave: historia de la educación, historia de las materias escolares, escuela primaria, aritmética, educación matemática.

\section{L'ARITHMÉTIQUE DANS LES ÉCOLES PRIMAIRES DE L'ÉTAT DU RIO GRANDE DO SUL DANS LA PREMIËRE MOITIÉ DU VINGTIĖME SIĖCLE: L'ENSEIGNEMENT PRÉVU}

\section{Résumé}

Depuis la proclamation de la République au Brésil, en 1889, jusqu'à la promulgation de la Loi organique sur l'enseignement primaire en 1946, les normes sur l'enseignement primaire furent la responsabilité des États qui composent la fédération. Le texte examine les normes établies dans cette période, dans l'état du Rio Grande do Sul, dans la période dite de la Première République (1889-1930) et la période nommée Era Vargas (1930-1945), en mettant l'accent sur les prescriptions pour l'enseignement de l'Arithmétique. Des connexions sont établies entre les lignes programmatiques et méthodologiques pour l'Arithmétique et les politiques gouvernementales pour le développement, la modernisation, la planification et le contrôle de l'enseignement primaire.

Mots-clé: histoire de l'éducation, histoire des disciplines scolaires, primaire, arithmétique, l'enseignement des mathématiques. 
constituição do ensino primário no Rio Grande do Sul, nos séculos 19 e 20,
tem sido objeto de estudos dedicados, sobretudo, à investigação das políticas
educacionais implementadas e aos processos de formação de professores. São menos frequentes os estudos que investigam as práticas escolares e muito poucos os que enfocam o ensino da Aritmética ou da Geometria nas escolas primárias.

$O$ projeto de pesquisa intitulado $A$ constituição dos saberes elementares matemáticos: a Aritmética, a Geometria e o Desenho no curso primário em perspectiva histórico-comparativa, iniciado em 2013, sob a coordenação do professor Wagner Rodrigues Valente, tem como objetivo analisar a trajetória de constituição dos ensinos de Aritmética, Desenho e Geometria em diferentes Estados brasileiros em perspectiva histórico-comparativa. No Rio Grande do Sul, constituiu-se um subprojeto regional ${ }^{1}$ dedicado à investigação sobre o ensino da Aritmética nas escolas primárias gaúchas no período republicano.

A primeira etapa da pesquisa foi dedicada ao inventário da legislação referente ao ensino primário $^{2}$, no período que se estende da proclamação da República até a aprovação do decreto-lei n. 8.529, de 2 de janeiro de 1946, conhecido como Lei Orgânica do Ensino Primário. O período compreende a Primeira República, em que os Estados da federação, originários das antigas Províncias do Império, gozavam de ampla autonomia e dispunham sobre a normatização do ensino primário, e a Era Vargas, durante a qual, apesar de todos os esforços de implantação de uma política educacional centralizada, a organização do ensino primário seguiu caminhos e regramentos próprios nos diferentes Estados.

A equipe regional cuidou, portanto, de inventariar e estudar a legislação que normatizou o ensino primário no Rio Grande do Sul de 1889 a 1946. A leitura dos documentos, "limitada para a compreensão das práticas realizadas e do funcionamento efetivo do ensino nas instituições escolares", era necessária, como argumenta Souza (2012), para o entendimento das "racionalidades instituídas e as tentativas do Poder Público de ordenamento e configuração do ensino" (p. 27).

A análise dos documentos foi iluminada pelo estudo das considerações e reconstruções já desenvolvidas por historiadores que tomaram o ensino primário no Brasil e no Rio Grande do Sul como objeto de investigação. Esse cotejamento entre a legislação estadual e resultados de estudos históricos já realizados permitiu o esboço inicial, aqui apresentado, de um quadro das prescrições oficiais relativas ao ensino da Aritmética no ensino primário, na primeira metade do século 20 , no Rio Grande do Sul.

\section{O ensino primário gaúcho nos primórdios da República}

O governo do Rio Grande do Sul foi, ao longo da Primeira República, dirigido pelo Partido Republicano Rio-Grandense - PRR - que, munido de um ideário positivista e representando um amplo bloco político, conquistou o governo dos dirigentes tradicionais apoiados pelos fazendeiros e charqueadores (Fonseca, 1993). Apesar da oposição dos

${ }^{1}$ No Rio Grande do Sul a pesquisa é coordenada por mim e pelas professoras Maria Cecilia Bueno Fischer, da Unisinos, e Monica Bertoni dos Santos, da PUCRS.

${ }^{2}$ A legislação citada no texto é acessível pelo site https://repositorio.ufsc.br/handle/123456789/98894. A coleta e a digitalização foram desenvolvidas pelos bolsistas de iniciação científica Fernando Augusto Braun Peixoto, da Ufrgs, e José Henrique de Oliveira, da PUCRS.

\begin{tabular}{|l|l|l|l|}
\hline Hist. Educ. [Online] & Porto Alegre & v. 18 & n. 44
\end{tabular}

\begin{tabular}{l|l} 
Set./dez. 2014 \\
\hline
\end{tabular}

p. $9-25$ 
federalistas e das crises deflagradas em 1893 e em 1923, o PRR conquistou uma relativa estabilidade política que permitiu, segundo Herrlein (2002), a implantação de um projeto de modernização social e econômica que teve como um de seus vetores o investimento no ensino.

Ao final do Império a educação pública no Rio Grande do Sul era esparsa e assistemática. As escolas primárias existentes eram, em sua maioria, particulares. Havia uma rede de escolas criadas pelos imigrantes alemães e italianos, especialmente na região colonial, ou mantidas pelas municipalidades (Peres, 2000). Em 1889, segundo Giolo (1994), das 618 aulas públicas criadas, apenas 385 estavam em funcionamento. Dessas, metade destinavam-se ao sexo masculino, cerca de um quarto ao sexo feminino e as restantes eram mistas. As instalações eram precárias e as aulas eram abertas e fechadas por motivos diversos. A procura, por parte das famílias, era pequena, e a frequência irregular, embora a legislação determinasse sua obrigatoriedade na idade dos 7 aos 15 anos.

O recrutamento de professores ocorria por uma variedade de estratégias, que incluíam concursos de seleção, constituição dos melhores alunos em monitores professores-adjuntos -, conferências pedagógicas, além da diplomação pela Escola Normal criada em 1869. Werle (2008) observa que a escola normal, no século 19, "não se instituiu como estabelecimento específico e diferenciado dos demais de ensino secundário, com currículo nítida e tecnicamente estruturado com objetivo de profissionalização docente" (p. 141). Em 1878 apenas 3,5\% das cadeiras públicas eram providas com professores normalistas.

A legislação determinava a organização do ensino primário em graus. O ensino de primeiro grau era aquele que se pretendia obrigatório e que deveria ser oferecido em todas as localidades, indistintamente. Segundo o relatório do vice-presidente da Província à Assembleia Legislativa Provincial, em 1857,

o ensino de $1^{\circ}$ grau, pois, compreende as noções que nenhum homem pode ignorar, sem prejuízo para si, e perigo para a sociedade. $\mathrm{O}$ do $2^{\circ} \mathrm{grau}$ sendo mais desenvolvido, habilita o menino a chegar ao ponto em que nele se possam manifestar disposições particulares para os estudos clássicos propriamente ditos, ou qualquer profissão. (apud Giolo, 1994, p. 37-38)

A Aritmética a ser ensinada nas escolas de primeiro grau era bastante simples, limitando-se às quatro operações com "números inteiros inferiores a cem" e a "noções elementares a respeito do nome e uso das medidas métricas" (Ato n. 141/1883, apud Arraiada; Tambara, 2004, p. 314). O ensino de segundo grau já era mais avançado e, no caso da Aritmética, estendia-se até as frações, razões e proporções, juros e descontos. Em 1883 apenas treze cidades, além da capital, contavam com escolas de segundo grau.

Instalada a República, o processo de reorganização do aparato administrativo foi retardado pela Revolução Federalista, que se estendeu de 1893 a 1895 . A reorganização do ensino público teve início em 1897, com a revisão dos vencimentos dos professores (Rio Grande do Sul, 1935). A partir daí a instrução pública e popular, tida como "uma das molas propulsoras do progresso social" (Bastos, 1994, p. 4), foi alvo de uma política consistente de expansão. Segundo Levine (apud Herrlein, 2002, p. 15), neste período a educação encabeçava as despesas públicas - exceto em tempos de guerra -, e os 
governos gaúchos despendiam uma fração maior das rendas com a educação do que o faziam os governos de São Paulo e de Minas Gerais.

Segundo Corsetti (1998), o ensino primário foi o principal alvo e instrumento de intervenção dos governos do PRR no campo da educação. Os regulamentos e programas instituídos neste período revelam, segundo a autora, os esforços de uniformização pedagógica, de centralização administrativa e de controle sobre o ensino público, com a preservação da liberdade concedida à iniciativa privada.

Pelo decreto n. 89, de 1897, se reorganizou o ensino primário no Estado, em moldes republicanos: "livre, leigo e gratuito" (art. $1^{\circ}$ ). Substituindo a organização do ensino em graus, o decreto previa a existência de escolas elementares, todas do mesmo grau, e de colégios distritais. Pelo decreto n. 130 , de 1898, se organizou o ensino das escolas elementares em três classes, cada uma com duas seções, cabendo ao professor classificar os alunos no início de cada ano letivo, segundo seu "grau de adiantamento" $\left(\right.$ art. $\left.2^{\circ}\right)$.

Os decretos anunciavam, portanto, um projeto ambicioso de um ensino primário estendido e homogêneo, de amplo acesso e com um programa que abarcava as noções antes atribuídas aos primeiro e segundo graus.

Os colégios distritais, por sua vez, eram instituições idealizadas a serem instaladas na capital e em outros municípios para ministrar um ensino mais avançado, devendo contar com uma biblioteca e o "material indispensável ao ensino prático do respectivo curso" (art. $4^{\circ}$ do decreto n. 89, de 1897). O ensino nos colégios deveria ser organizado em três classes sucessivas, em que preponderavam o Português e a Matemática, cada qual com seis horas semanais (decreto n. 385, de 1901). Os colégios existentes foram convertidos, em 1906, em escolas complementares, de "caráter prático e profissional com o fim de desenvolver o ensino elementar e preparar candidatos ao magistério público primário" (decreto estadual n. 874, de 1906).

Buscava-se constituir um ensino especializado, dedicado à formação de professores. Já em 1909, entretanto, o decreto n. 1.479 alertava em seu preâmbulo que as escolas complementares existentes não preenchiam "o fim para que foram creados, exceptuado o da capital", não sendo possível "sem modificações radicaes nos programmas daqueles estabelecimentos, tornal-os uteis". Foi mantida a Escola Complementar de Porto Alegre, herdeira da antiga Escola Normal, dedicada à formação de professores.

O decreto n. 1.479, de 1909, extinguiu os demais colégios complementares e criou uma nova figura, a dos colégios elementares: escolas urbanas, com classes graduadas pela idade e grau de conhecimento, reunindo "tantos professores quantos [...] necessários" (art. $2^{\circ}$ do decreto n. 1.479, de 1909). A Circular n. 978, de junho de 1914, determinava que todas as classes dos colégios elementares fossem mistas e que o mesmo ensino deveria ser ministrado pelos mesmos professores a meninos e meninas (Rio Grande do Sul, 1935).

Neste mesmo ano foram criados, a partir da reunião de escolas isoladas e da conversão de quatro colégios complementares, nove colégios elementares (Luchese (2013). A condição para a instalação dos colégios era a cedência, pelas municipalidades, de instalações. Entretanto, segundo a autora, essas condições permaneceram, em geral, precárias, pelo menos até a década de 1920. 
Em 1915 foi criada a figura do grupo escolar, como reunião de aulas, devendo ser atendido por pelo menos três professores. Grupos escolares distinguiam-se dos colégios pelo número de alunos: eram convertidos em colégios elementares quando atingiam 200 ou mais alunos, e colégios retroagiam à condição de grupos quando esse número caía abaixo de 200.

Predominavam, entretanto, as escolas isoladas, herdeiras das antigas aulas públicas, em que um único professor - em geral professora - ministrava a um grupo de crianças de idades variadas, em salas alugadas, um ensino que pode ser presumido como bastante elementar. As escolas eram classificadas segundo entrâncias, sendo os novos professores designados para as de primeira entrância, situadas nas localidades mais distantes dos centros urbanos.

Para Luchese (2013), os colégios elementares teriam sido a versão local do modelo denominado, no resto do país, de grupo escolar, por oferecerem um ensino seriado, pela autoridade que lhes foi atribuída e porque se constituíam em referência de ensino. Professores desses colégios gozavam de maior reconhecimento social, assumindo tarefas no processo de expansão, como a participação em bancas examinadoras finais de escolas isoladas.

Mas é importante observar que as condições desses colégios eram muito diversas daquelas dos grupos escolares instituídos em São Paulo, a partir de 1893, pela reunião de escolas preliminares, regidas por professores normalistas e dotadas de todo um aparato administrativo (Souza, 2012). No Rio Grande do Sul a formação de professores havia sido atribuída à Escola Complementar de Porto Alegre, mas a normatização detalhada dessa formação ocorreu apenas em 1929, com o decreto n. 4.277, que regulamentou o ensino normal e complementar no Estado. Segundo Luchese (2013), muitos alunos dos colégios elementares tornaram-se professores após concluírem os estudos, o que atesta a permanência de processos de recrutamento que passavam ao largo dessa formação institucionalizada.

Além disso, há indícios de que o ensino ministrado nos colégios não era propriamente um ensino seriado. Peres (2000) cita o relatório de uma diretora, do ano de 1927, que afirmava persistir no seu colégio, apesar da reunião de 13 professoras, o ensino individual, já que em uma mesma classe havia alunos de vários graus. 0 Regulamento da Instrução Pública de 1927 previa a organização do ensino em três classes - inferior, média e superior -, entretanto, não obrigava o desdobramento das classes em seções (decreto n. 3.898, 1927, art. 27).

Em 1927 os índices de escolarização do Rio Grande do Sul haviam sido expressivamente elevados, de cerca de 23\%, em 1907 (Targa, 1996), para 73\% da população em idade escolar, segundo dados da Directoria Geral de Estatística do Ministério da Agricultura, Indústria e Comércio. Os patamares eram superiores aos dos demais Estados: os índices para o Paraná, São Paulo e Distrito Federal, eram, respectivamente de 70\%, 60\% e 50\% (Rio Grande do Sul, 1935).

Mas ainda predominavam as escolas isoladas: 1981 no ano de 1922. Também eram expressivos os números de escolas municipais e de escolas particulares, 540 e 427 , respectivamente, nesse ano (Araújo, 2012).

Ao final do governo de Borges de Medeiros, em janeiro de 1928, o Rio Grande do Sul contava com 46 colégios elementares e 33 grupos escolares, quando São Paulo tinha 
já 289 grupos escolares (Souza, 2012). Frente aos demais Estados, o Rio Grande do Sul caracterizava-se por uma rede de ensino bastante pulverizada. O modelo do ensino seriado, com turmas organizadas segundo idades e adiantamentos, disseminava-se, mas lentamente.

\section{A Aritmética nos programas de ensino durante a Primeira República}

O decreto n. 89 , de 1897, anunciava que o ensino elementar deveria abranger "contar e calcular. Arithmetica pratica até a regra de tres, mediante o emprego, primeiro dos processos espontaneos, e depois dos processos systematicos" e o "systema metrico precedido do estudo da geometria pratica (tachymetria)" (art. $5^{\circ}$ ). O programa para o ensino elementar, estipulado no decreto n. 239 , de 1899, incluía o estudo da Aritmética, da Geometria Prática e do Desenho.

Em consonância com a orientação positivista e o viés modernizante e cientificista da administração estadual, o regimento interno das escolas elementares valorizava o ensino da Aritmética e da Geometria, determinando a atribuição diária de "tres quartos de hora para arithmetica ou geometria pratica e para os exercícios que com essas materias se relacionam" (decreto n. 130,1898 , art. $8^{\circ}$ ).

O programa para o ensino da Aritmética projetava um estudo dos números gradativamente complexificado, iniciando pela contagem, soma e subtração mental, estendendo-se à multiplicação e divisão e aos algoritmos das operações na pedra ou na lousa, passando pelas frações decimais e ordinárias, pelo uso do sistema métrico decimal e avançando, na terceira classe, até as regras de três simples e composta, a extração da raiz quadrada e da raiz cúbica de números inteiros, decimais e fracionários.

O caráter prático atribuído ao ensino da Aritmética era explicitado na recomendação do cálculo com números concretos - representações de medidas do sistema métrico ou de outras grandezas quantificáveis -, e na orientação reiterada para a resolução de problemas práticos. Prescrevia-se o estudo de "problemas praticos sobre as quatro operações em números inteiros e decimaes, applicando a reducção à unidade"; "applicação das regras aprendidas [sobre frações] em problemas praticos"; "regra de juros simples em problemas praticos; avaliação dos juros, capital, taxa e tempo"; "regra de sociedade simples e composta, em problemas praticos e applicação do methodo de reducção à unidade"; "problemas praticos com applicação da raiz quadrada" (decreto n. 239, 1899, p. 265-273).

As aplicações se estendiam à Geometria, no caso da raiz quadrada:

Avaliação da hypothenusa de um triangulo rectangulo; avaliação da área de um triangulo, sendo dados os três lados; avaliação do lado do quadrado, sendo dada a área; avaliação do raio e do diametro, sendo dada a área do circulo. (Decreto n. 239, 1899, p. 273)

O decreto n. 1.575, de 1910, introduziu pequenas modificações nesse programa. Indicava a recapitulação de conteúdos: "ampliação do conhecimento sobre as duas primeiras operações"; "problemas de recapitulação do programma da primeira secção" (decreto n. 1.575, 1910, p. 3, 13). Também sugeria uma abordagem abreviada de alguns tópicos, ao mencionar "rudimentos das duas primeiras operações" ou "pequenos problemas praticos sobre frações" (decreto n. 1.575, 1910, p. 1, 7). 
O decreto n. 3.903, de 1927, reiterava o caráter eminentemente prático do ensino de Aritmética: "A theoria dar-se-á após a resolução de problemas que, habitualmente, vae o aluno resolver na pratica da vida" (p. 540).

Embora de caráter prático, o programa para a Aritmética, em termos dos conteúdos ou objetivos listados, era bastante ambicioso se comparado ao programa prescrito para as escolas de primeiro grau no período imperial. Contemplava as quatro operações com frações ordinárias, decimais, o estudo das proporções, das raízes quadradas e cúbicas. $A$ predominância do ensino em escolas isoladas, até meados dos anos 1920, sugere, contudo, que o programa em geral praticado era mais modesto que o prescrito. A decisão dos professores do Instituto Júlio de Castilhos, em 1911, de criarem um curso primário devido à precariedade da formação dos alunos que acorriam ao curso secundário oferecido pela instituição (Esperança, 2010), também é um indício de que as aprendizagens escolares não correspondiam aos programas decretados.

Desde as primeiras normatizações o recurso ao método intuitivo era enunciado como determinação oficial, precedendo o enunciado dos programas, devendo servir "o livro apenas de auxiliar" (decreto n. 89, 1897, art. $6^{\circ}$ ). Tal como era referido nos documentos oficiais, o método intuitivo contrapunha-se ao ensino baseado na preleção e na repetição e ancorava-se mais na observação do real do que na audição do professor ou na memorização do texto escrito:

Art. $3^{\circ}$ - É adoptado o methodo intuitivo e pratico, começando pela observação de objectos simples, para elevar-se depois à ideia abstracta, à comparação, à generalisação e ao raciocínio, vedando-se qualquer ensino empirico, fundado exclusivamente em exercicios de memoria. (Decreto $n$. 239, 1899)

O apelo ao método intuitivo desdobrava-se em várias recomendações específicas: no recurso ao cálculo mental "primeiro com o auxilio dos dedos, de pedrinhas, de grãos etc., depois sem este auxilio"; no estudo do "systema metrico decimal, empregando, sempre que fôr possivel, o methodo intuitivo: metro, metro quadrado, metro cubico, litro, grammo"; na apresentação das frações ordinárias a partir da "ideia de metade, terço, quarto, etc. por meios intuitivos" (decreto n. 239, 1899).

A determinação do emprego do método intuitivo foi reiterada no decreto n. 3.903 , de 1927, em uma redação que praticamente reproduz a do decreto de 1899:

Art. $3^{\circ}$ - Será constantemente empregado o methodo intuitivo, começando pela observação de objectos simples para elevar-se depois à ideia abstracta, à comparação, à generalisação e ao raciocinio, vedando-se qualquer ensino empirico, fundado exclusivamente em exercicios de memoria.

O mesmo decreto n. 3.903, de 1927, estipulava que o professor devia fazer explicações orais e propor "questões praticas, para serem resolvidas pelos alumnos" (art. $\left.5^{\circ}\right)$.

Os apelos reiterados ao emprego do método intuitivo nos documentos oficiais indicam que, embora aconselhado já desde o período imperial, não havia penetrado nas práticas escolares. Uma persistente inclinação dos professores pelo ensino livresco é sugerida pela redação da Circular n. 1873, de janeiro de 1916, da Secretaria do Interior e 
do Exterior:

O ensino deve ter um cunho pratico, concreto e o mais possivel intuitivo e não abstracto e theorico - de sorte a deixar o aluno embaraçado deante do mais simples problema. Encontram-se creanças que analysam logicamente um trecho com certa facilidade e que, entretanto, são incapazes de reproduzir de viva voz ou por escripto o mesmo trecho, de redigir, com correcção e com senso, duas linhas siquer. É preciso que o professor do collegio elementar se sinja ao programma e tenha bem em vista que não fica em plano inferior, dando aos seus alumnos educação solida e abandonando programmas mais ou menos sumptuarios, que roubam o tempo em detrimento do fim utilitario e pratico da educação. (Apud Rio Grande do Sul, 1935, p. 247)

O descompasso entre os métodos prescritos e praticados suscita questões sobre a formação dos professores. De um lado, pode-se supor que os professores reproduziam os métodos pedagógicos que haviam vivenciado como alunos, como ocorreu em outros momentos e lugares. De outro lado, pode-se aventar a hipótese de que o recurso ao ditado e à memorização encobriam a pouca desenvoltura com os conteúdos abordados.

Os candidatos ao magistério público deveriam, de acordo com o decreto n. 3.975, de 1927, prestar provas orais sobre cada uma das matérias. O programa de Matemática incluía, além dos conteúdos de aritmética prescritos para o ensino elementar, tópicos de Álgebra, como equações de segundo grau e bi-quadradas, binômio de Newton, fórmulas de Cramer e outros métodos de resolução de sistemas de equações. A Geometria do ensino elementar era acrescida de um capítulo de Trigonometria.

Entretanto, o decreto n. 3.898, de 1927, esclarecia, no art. 82, que os alunosmestres, oriundos das escolas complementares, ficavam dispensados das provas teóricas nos concursos para as vagas de professores efetivos. E qual era a Matemática estudada no ensino complementar?

O decreto n. 1.479, de 1909, determinava que o ensino complementar abrangeria "aritmética, estudo completo; álgebra até equações do $2^{\circ}$ grau inclusive; geometria a três dimensões" (artigo $9^{\circ}$ ). A Aritmética estudada pelos professores, portanto, era a mesma que deveriam ensinar, acrescida de rudimentos de Álgebra.

O decreto n. 4.277, de 1929, estabeleceu nova regulamentação, instituindo o ensino normal, a ser oferecido na Escola Normal de Porto Alegre, e o ensino complementar, com duração de três anos, a ser oferecido nas escolas complementares públicas ou equiparadas. No programa do curso complementar, a Aritmética figurava em cada um dos três anos, a Álgebra e a Geometria no segundo e no terceiro anos. Estabelecia-se também um rigoroso e complicado sistema de avaliação dos alunos que incluía três sabatinas, além dos exames finais para cada disciplina.

Entretanto, já no ano seguinte, a aplicação deste sistema seria suspensa em virtude do processo conhecido como Revolução de 1930, que culminou com a deposição do presidente Washington Luís em 24 de outubro. No mesmo dia, o secretário do Interior e Exterior, Oswaldo Aranha, no exercício do governo estadual em substituição ao governador Getúlio Vargas, pelo decreto n. 4.621, encerrou as aulas no dia 31 de outubro e dispensou dos exames finais todos os estudantes que houvessem obtido média cinco nas sabatinas. 
O mesmo expediente se repetiria em 1935, a pretexto da comemoração do centenário da Revolução Farroupilha (decreto n. 6.048), e novamente em 1936 (decreto n. 6.320), o que sugere que havia uma pressão importante, por parte dos estudantes, para o rebaixamento das exigências acadêmicas, mas, também, que o relaxamento das regras, do mesmo modo que as transferências de professores para cidades maiores ou a atribuição de cargos de direção e inspeção, era moeda de troca corrente usada pelo governo estadual para ampliar sua base de apoio.

Enfim, a documentação rarefeita produzida no período da Primeira República e as limitações do inventário de fontes constituído até o momento, no âmbito do projeto de pesquisa, não autorizam afirmações conclusivas sobre a Aritmética ensinada nas escolas primárias gaúchas. Entretanto, são vários os indícios de que os programas, assim como o conjunto das normatizações, expressavam mais a vontade dos governos de controlar e imprimir uma tendência modernizante ao ensino primário do que um regramento ordenador do ensino praticado.

\section{O ensino primário gaúcho na Era Vargas}

Os anos 1930 caracterizaram-se pela sucessão de governos estaduais identificados com a política getulista. Flores da Cunha, interventor nomeado por Getúlio Vargas em 1930, exerceu o mandato como governador eleito de 1935 a 1937 . Rompido com o governo federal, e no contexto de instauração do Estado Novo, teve seu mandato interrompido e sucedido pelo do interventor Cordeiro de Farias (1938-1943).

Durante o governo de Getúlio Vargas (1928-1930) e o primeiro mandato de Flores da Cunha (1930-1935) houve importante expansão da rede escolar pública e, em especial, do ensino seriado. Ao longo desses sete anos foram criados sete colégios elementares e setenta e um grupos escolares, totalizando 53 colégios e 104 grupos.

Mas foi na segunda gestão de Flores da Cunha, como governador eleito, que se iniciou um empreendimento de reordenamento e modernização do aparato escolar, prosseguido e aprofundado no governo do interventor Cordeiro de Farias.

Em 1935 foi criada a Secretaria de Estado dos Negócios da Educação e Saúde Pública, pelo decreto n. 5.969, e o Conselho Estadual de Educação, pelo decreto $n$. 6.105. Em 1938, pelo decreto n. 7.641, criaram-se Delegacias Regionais de Ensino, vinculadas às dez regiões escolares em que o Estado foi dividido.

Em 1938, pelo decreto n. 7.640, se organizou e regulamentou a carreira do magistério público primário estadual. Por meio dele, segundo Bica e Corsetti (2012), "buscou-se a reorganização da profissionalização docente, a normatização de questões pedagógicas, além da promoção de mudanças educacionais no Estado do Rio Grande do Sul" (p. 251). O decreto estabeleceu um regramento e calendário anual de concursos, vinculado ao funcionamento das escolas normais e complementares, detalhava critérios e procedimentos para transferências, dos professores, das localidades mais afastadas para as cidades, bem como critérios e procedimentos para a designação dos diretores de escola e outros cargos. Instaurava, enfim, toda uma normatização presumidamente baseada no critério da impessoalidade, afastando as interferências e perseguições segundo interesses ou afinidades partidárias: "Ontem, lutas de competições mesquinhas, dependencia moral, preterições injustas. Hoje, esforço honesto de concorrencia profissional, vitoria autonoma, reconhecimento do mérito verdadeiro (Gayer, 1939, p. 26). 
Um novo Regimento Interno das Escolas Primárias foi estabelecido pelo decreto $\mathrm{n}$. 7.929, de 1939. As escolas primárias foram agrupadas em dois tipos: escolas isoladas e grupos escolares. Neste ano o Estado já contava com 351 grupos, o dobro do número de grupos e colégios existentes em 1935, e 797 escolas isoladas (Gayer, 1939).

Os graus do ensino primário foram redefinidos e denominados como anos, estendendo-se do primeiro ao sexto ${ }^{3}$. O decreto estabelecia requisitos mínimos de frequência e critérios de promoção dos alunos para 0 ano seguinte. Detalhava calendários, horários e práticas, como o ingresso dos alunos no prédio "acompanhados pelo professor e ao som de uma canção ou marcha" (art. 11).

O regimento estabelecia, também, condições gerais de funcionamento das escolas. Deveriam estar equipadas com bibliotecas, deveriam contar com um quadro de professores substitutos em número proporcional ao dos professores efetivos. Por outro lado, autorizava o funcionamento da escola em turnos reduzidos de três horas, "quando a matrícula elevada e a falta de acomodações suficientes no prédio tornarem necessário o tresdobramento do dia escolar" (art. $\left.9^{\circ}\right)$.

Todo este novo arcabouço institucional visava, segundo Peres (2000), não apenas a expansão ordenada da rede e o "controle do andamento dos trabalhos nos estabelecimentos de ensino", mas a implantação de "uma orientação pedagógica científica" (p. 129).

\section{A Aritmética nos novos programas de ensino}

O decreto n. 8.020, de 1939, estabeleceu os novos programas mínimos a serem adotados nas escolas. Importante observar que, de acordo com a visão cientificista adotada, os programas eram declarados experimentais $\mathrm{e}$

sujeitos a revisões periódicas, a fim de receberem as emendas determinadas pelos resultados de pesquisas, inquéritos e observações relativas às exigências do meio e aos interesses e possibilidades reais de aprendizagem de nossos escolares. (Decreto n. 8.020, art. $2^{\circ}$ )

Embora experimentais eram detalhados e continham objetivos gerais da matéria, os objetivos específicos, o mínimo essencial e a normativa de cada disciplina, para cada um dos seis anos do ensino primário. A Matemática aparecia como disciplina, englobando a Aritmética e a Geometria.

O programa de 1939 era tão extenso quanto aquele de 1899: ao final de seis anos esperava-se que os alunos operassem com frações decimais e ordinárias, percentagens, raízes quadradas e cúbicas, unidades de medida do sistema métrico decimal e outras mais antigas, avaliassem a área e o perímetro do círculo e de polígonos regulares de até oito lados.

O esforço de, ao mesmo tempo, orientar e controlar a ação das professoras é evidenciado no detalhamento com que era descrito o mínimo essencial para cada ano, em que as dificuldades, os aprofundamentos ou ampliações deviam ser introduzidos gradativamente. Por exemplo, no primeiro ano, entre vários itens, aparecia a "noção de metade" (decreto n. 8.020, p. 72), no segundo ano a de "meios, terços, quartos etc." (p.

${ }^{3}$ O decreto n. 491, de 23 de fevereiro de 1942, extinguiu o sexto ano do ensino primário no Estado. \begin{tabular}{|l|l|l|l|l|l|}
\hline Hist. Educ. [Online] & Porto Alegre & v. 18 & n. 44 & Set./dez. 2014 -25
\end{tabular} 
85) e no terceiro ano a "noção de fração, como parte do inteiro" (p. 95). No segundo ano, aparecia o item "divisões com divisor simples e dividendo até 100" (p. 85); no terceiro ano, a "divisão de números quaisquer" (p. 95).

O apelo ao concreto e à intuição reaparecia no objetivo enunciado de proporcionar à criança, "em ação direta e pessoal sobre as cousas, o material concreto e vivido que servirá de base às abstrações matemáticas" (decreto n. 8.020, p. 71). Esse apelo, entretanto, aparecia imerso em um conjunto mais amplo de enunciados que revelam a influência da emergente Psicologia Educacional e da Escola Nova, que se difundiu no Brasil, sobretudo a partir dos anos 1920 (Peres, 2000).

O ensino da Matemática, neste novo discurso, visava a "aquisição de conceitos", o "estabelecimento correto de relações numéricas" (decreto n. 8.020, p. 72), o "seguro domínio das coordenações aritméticas fundamentais" (p. 73). A ação do professor deveria estar baseada na compreensão do pensamento da criança, ao tomar como referência "os conhecimentos de ordem matemática que a criança possue ao ingressar na escola" ( $p$. 71) e "descobrir as dificuldades ainda não dominadas pelo aluno" (p. 73).

A abstração deveria ser construída a partir da manipulação de objetos, tal como a "contagem concreta" (decreto n. 8.020, p. 85), através das dramatizações e das referências às experiências vividas pelas crianças. Deveriam ser valorizados os "problemas reais surgidos na própria vida das crianças" (p. 73), como os de "despesa, merenda, transporte, material escolar, etc." (p. 85), "sendo de conveniência levar os alunos a se identificarem com os personagens do problema" (p. 96). O concreto e o vivido, contudo, não deviam ser apenas pontos de partida para a aprendizagem, considerando-se que é a realidade que "dá significação" aos conceitos (p. 85). Atividades de "reconhecimento das moedas" e "práticas de troco", simulando práticas extraescolares, eram ao mesmo tempo recursos didáticos e expressões do caráter "utilitário" (p. 72,85$)$ atribuído ao ensino da Matemática.

As atividades deveriam ser capazes de "provocar esforço vitalizado dos alunos" (decreto n. 8.020, p. 96), e com esse intuito propunha-se o recurso aos jogos aritméticos, às dramatizações de compra e venda, à feira escolar ou bazar, aos projetos, excursões e visitas, aos "problemas formulados pelos próprios alunos" (p. 85) e às "tabelas de preços organizadas ou recolhidas pelos alunos" (p. 85).

Esse repertório de orientações didáticas não visava apenas à motivação dos alunos: esperava-se que o "conhecimento dos conceitos" viesse acompanhado da "automatização" dos procedimentos de cálculo (decreto n. 8.020, p. 85). Em 1942, um artigo publicado na Revista de Ensino, de ampla circulação, alertava para os riscos dos "extremismos metodológicos" (Souza, apud Bastos, 2005, p. 150):

Com o movimento de renovação escolar, condenando-se a memorização puramente passiva dos conteúdos, caiu-se no extremo oposto e quase foi completamente abandonado o treino sistemático da tabuada. Daí resultou um decréscimo assustador da eficiência do cálculo. (Souza, apud Bastos, 2005, p. 150)

O estudo da psicologia da criança e o recurso aos métodos ativos visavam, sobretudo, a um ensino eficiente. 


\section{Um ensino orientado para os exames}

$\mathrm{Na}$ busca da eficiência e do controle sobre as atividades escolares, constituiu-se um aparato crescentemente especializado. Em 1942 foi criada a Secretaria de Educação e Cultura e, no interior dela, o Departamento de Educação Normal e Primária.

Em 1943, sob a influência do Instituto Nacional de Estudos Pedagógicos - Inep - foi criado o Centro de Pesquisas e Orientação Educacionais - CPOE -, a partir da transformação da Secção Técnica da antiga Diretoria Geral de Instrução Pública. Segundo Quadros (2006), os técnicos do CPOE preocuparam-se com o desenvolvimento de pesquisas sobre o ensino-aprendizagem e com o

desenvolvimento profissional do magistério, que envolvia o planejamento, a coordenação e a avaliação do trabalho do professor, com vistas a alcançar a produção de uma força de trabalho disciplinada e mobilizada para efetivar a renovação educacional, na direção da implantação dos princípios escolanovistas. (p. 126)

Entre os mecanismos utilizados na supervisão e orientação aos trabalhos escolares podem ser citados: a instituição, já em 1940, dos Círculos de Estudos, que reuniam diretores ou orientadores das escolas para discussões administrativas ou pedagógicas; a exigência da apresentação, por parte das escolas, de planejamentos e relatórios; a oferta de cursos, seminários ou sessões de estudo para os professores (Quadros, 2006).

O controle externo sobre a atividade escolar foi, provavelmente, exercido com maior eficácia pelas provas objetivas, elaboradas pelo CPOE de 1943 a 1965 e aplicadas em todas as escolas ao final de cada ano letivo, como exames finais que aferiam os conhecimentos dos estudantes e decidiam sobre sua promoção para o ano seguinte. Os objetivos enunciados eram os de "garantir o equânime tratamento dos alunos, exigindoIhes os mesmo padrões mínimos de aproveitamento", e de "tornar comparáveis os resultados das diferentes classes" (Peres, 2000, p. 260).

A aplicação destas provas produzidas externamente às escolas resultava em índices de reprovações elevados, especialmente no primeiro ano primário: em 1950 apenas 54\% dos alunos do primeiro ano foram aprovados (Moreira, 1955).

Em visita ao Estado nos anos 1950, para estudo encomendado pelo Inep, Roberto Moreira (1955), baseado em entrevistas e observações de sala de aula, observou que as provas objetivas determinavam, largamente, a ação das professoras. Instadas, de um lado, à adoção dos métodos ativos e, de outro, pressionadas pelas provas que também avaliavam a eficiência de sua prática docente, as professoras orientavam o ensino, sobretudo, para a aprovação dos alunos nos exames:

Tal processo de utilizar duas metodologias, uma bem mais ativa, requerendo atividades extraclasse, e outra bem mais formalista e automatizadora, encontramos em oito dos grupos escolares que visitamos. Foi impossível verificar, até que ponto, ambas tinham entre si alguma correlação. O que nos ficava patente é que as professoras, desejosas de aplicar bons métodos de ensino, se viam na contingência de ensaiá-los, uma vez por outra, quase a título de recreação, mas sem deixar de conseguir as memorizações e mecanismos mentais que seriam testados nos exames. Este segundo aspecto era, não há dúvida, o mais importante, para a professora. (Moreira, 1955, p. 131) 
Moreira (1955) registra a prática comum das professoras de se dedicarem no último bimestre aos alunos que teriam chance de êxito nos exames. Nem todos os alunos faziam os exames finais: surgia então a figura do aluno inabilitado, reprovado antecipadamente, em função de um desempenho considerado demasiadamente fraco. Naturalizava-se a distribuição dos alunos em turmas de fortes e fracos: "chegamos a notar certo fatalismo por parte das professoras: quem tivesse a seu cargo um primeiro ano fraco, já estava de antemão satisfeito com a possibilidade de uma grande percentagem de reprovações" (p. 137).

O foco nas provas é uma das explicações para a ênfase na automatização dos cálculos que transparece nos depoimentos coletados por Peres (2000):

Eles aprendiam tudo que era de Matemática. Mas a tabuada sempre na ponta da língua. Tinha que ser! [...] A gente fazia jogo. Três vezes quatro, mais cinco, menos dois, vezes oito e assim se fazia. [...] Prá ver quem ganhava. Aquilo era uma coisa medonha! Eles gostavam. Sete vezes oito? Um gritava: cinqüenta e seis. Menos dois, mais quatro, vezes cinco, dividido por três. Quer dizer que aquilo exercitava também, né? Era muito bom! (D. Maria de Lourdes, apud Peres, 2000, p. 381).

A diretora não queria já naquele tempo, ela não queria, por exemplo, decorar a tabuada. Ela, assim, achava que em aula a gente podia fazer exercício, cantando com eles, falando em voz alta, eles decoravam, né? (D. Sueli, apud Peres, 2000, p. 381)

A pedagogia que aparece como predominante nesses depoimentos era a dos exercícios de fixação: "Se era Matemática, ensinava problema, conta, expressões, equações, já mais adiantados, né? Muda de sinais, aquilo. Eles pegavam, normalmente pegavam [...]. Fazia muito exercício" (D. Sueli, apud Peres, 2000, p. 377).

Instalava-se, assim, uma educação Matemática que, incorporando elementos de dramatização, músicas e jogos, estava dirigida para a memorização da tabuada, para os exercícios de fixação, para a habilidade no cálculo e na manipulação de expressões numéricas. Um ensino, enfim, voltado para as provas.

\section{Considerações finais}

Nos anos que precederam a decretação da Lei Orgânica do Ensino Primário, que normatizou o ensino primário em âmbito nacional, o Rio Grande do Sul consolidava sua própria rede e um aparato de controle, supervisão e assessoria técnica ao ensino.

O ensino graduado estabelecia-se como padrão de ensino primário e, com ele, instalava-se e naturalizava-se a lógica da seleção dos alunos, mediante a promoção ou retenção.

Os programas de ensino recomendavam os métodos ativos, o foco nos conhecimentos e interesses dos alunos, enquanto as provas, na interpretação das professoras, avaliavam a destreza no cálculo e no manejo da escrita Matemática.

A escolarização era prolongada até os cinco anos, mas não para todos. Apenas os bons alunos chegavam ao final do ensino primário, que assumia, paulatinamente, uma nova função: a de preparar os alunos para o concorrido exame de admissão ao ginásio, em que a prova de Matemática tinha importante papel seletivo. 
As provas objetivas ocupavam um lugar de destaque na nova configuração do ensino primário. De um lado, constituíam-se em instrumento de prescrição do ensino, mais eloquente do que os programas. De outro, naturalizavam a seleção, responsabilizando os alunos pelo seu sucesso ou fracasso. As trajetórias escolares dos estudantes eram, desde cedo, definidas segundo a aprendizagem da Aritmética, da leitura e da escrita. Segundo o discurso oficial, aprendia-se Matemática para a vida, na prática, aprendia-se Matemática para sobreviver na escola.

\section{Referências}

ARAÚJO, José Carlos Souza. Republicanismo e escola primária nas mensagens dos presidentes de estado de Minas Gerais (1891-1930). In: ARAÚJO, José Carlos Souza; SOUZA, Rosa Fátima de; PINTO, Rubia-Mar Nunes (orgs.). Escola primária na primeira república (1889-1930): subsídios para uma história comparada. Araraquara: Junqueira \& Marin, 2012, p. 100-150.

ARRIADA, Eduardo; TAMBARA, Elomar (orgs.). Leis, atos e regulamentos sobre educação no período imperial na Província de São Pedro do Rio Grande do Sul. Brasília: Inep/SBHE, 2004.

BASTOS, Maria Helena Câmara. A Revista do Ensino do Rio Grande do Sul (1939-1942): o novo e o nacional em revista. Pelotas: Seiva, 2005.

BICA, Alessandro Carvalho; CORSETTI, Berenice. A sistematização da educação riograndense durante o Estado Novo: o caso do decreto n. 7.640, de 28 de dezembro de 1938. Hist. Educ. (Online), Porto Alegre, v. 16, n. 38, 2012, p. 250-276.

CORSETTI, Berenice. Controle e ufanismo: a escola pública no Rio Grande do Sul (1899/1930). Hist. Educ. (Online), Porto Alegre, n. 4, 1998, p. 57-75.

ESPERANÇA, Antonio Cesar dos Santos. O ensino de matemática no Instituto Júlio de Castilhos: um estudo sobre as provas do curso complementar. Porto Alegre: Ufrgs, 2012. 154f. Dissertação (mestrado em Ensino de Matemática). Programa de Pós-Graduação em Ensino de Matemática, Universidade Federal do Rio Grande do Sul.

FONSECA, Pedro Cezar Dutra. Revolução federalista: uma interpretação. In: FRANCO, Sérgio da Costa et al. (orgs.). Pensar a revolução federalista. Rio Grande: Furg, 1993, p. 23-26.

GAYER, Olga Acauan. A instrução pública no Rio Grande do Sul. Jornal do Estado, Porto Alegre, n. 422, 1939, p. 26-27.

GIOLO, Jaime. Lança e grafite: a instrução no Rio Grande do Sul - da primeira escola ao final do império. Passo Fundo: UPF, 1994.

HERRLEIN, Ronaldo. A peculiaridade da transição capitalista no Rio Grande do Sul (1889-1930). ENCONTRO DE ECONOMIA GAÚCHA, 1, 2002, Porto Alegre. Anais ... Porto Alegre: PUCRS; FEE, 2002, p. 1-23. 
LUCHESE, Terciane Ângela. Da prescrição à realização: os colégios elementares como um novo modelo de escola primária no Rio Grande do Sul (1909-1927). CONGRESSO BRASILEIRO DE HISTÓRIA DA EDUCAÇÃO, 7, 2013, Cuiabá. Anais ... Cuiabá: SBHE/UFMT, 2013, p. 1-14.

MOREIRA, J. Roberto. A escola elementar e a formação do professor primário no Rio Grande do Sul. Rio de Janeiro: MEC/Inep, 1955.

PERES, Eliane Teresinha. Aprendendo formas de pensar, de sentir e de agir: a escola como oficina da vida - discursos pedagógicos e práticas escolares da escola pública primária gaúcha (1909-1959). Belo Horizonte: UFMG, 2000. 493f. Tese (doutorado em Educação). Programa de Pós-Graduação em Educação, Universidade Federal de Minas Gerais.

QUADROS, Claudemir de. Reforma, ciência e profissionalização da educação: o Centro de Pesquisas e Orientação Educacionais do Rio Grande do Sul. Porto Alegre: Ufrgs, 2006. 429f. Tese (doutorado em Educação). Programa de Pós-Graduação em Educação, Universidade Federal do Rio Grande do Sul.

RIO GRANDE DO SUL. Directoria Geral da Instrucção Publica. Almanack escolar do Rio Grande do Sul. Porto Alegre: Selbach, 1935.

SOUZA, Rosa Fátima de. As escolas públicas paulistas na primeira república: subsídios para a história comparada da escola primária no Brasil. In: ARAÚJO, José Carlos Souza; SOUZA, Rosa Fátima de; PINTO, Rubia-Mar Nunes (orgs.). Escola primária na primeira república (1889-1930): subsídios para uma história comparada. Araraquara: Junqueira \& Marin, 2012, p. 23-77.

TARGA, Luiz Roberto Pecoits. Permanências na longa duração. In: TARGA, Luiz Roberto Pecoits (org.). Gaúchos e paulistas: dez escritos de história regional comparada. Porto Alegre: FEE, 1996, p. 271-280.

WERLE, Flávia Obino Corrêa. Escola normal no Rio Grande do Sul, século XIX. In: ARAÚJO, José Carlos Souza; FREITAS, Anamaria Gonçalves Bueno de; LOPES, Antônio de Pádua Carvalo (orgs.). As escolas normais no Brasil: do império à república. Campinas: Alínea, 2008, p. 123-144. 
ELISABETE ZARDO BÚRIGO é professora na Universidade Federal do Rio Grande do Sul e doutora em Educação pela Universidade de São Paulo. É pesquisadora do Grupo de Pesquisa de História da Educação Matemática no Brasil - Ghemat, do Grupo de Trabalho Educação Matemática no Ensino Superior da Sociedade Brasileira de Educação Matemática e do Topic Study Group The history of the teaching and learning of mathematics do International Congress on Mathematical Education - Icme.

Endereço: Avenida Bento Gonçalves, 9500 - 91509-900 - Porto Alegre - RS - Brasil. E-mail: elisabete.burigo@ufrgs.br.

Recebido em 25 de março de 2014.

Aceito em 27 de junho de 2014. 